\title{
Importance of Efferent Arteriolar Vascular Tone in Regulation of Proximal Tubule Fluid Reabsorption and Glomerulotubular Balance in the Rat
}

\author{
IEKUNI ICHIKAWA and BARRY M. BRENNER, Laboratory of Kidney and \\ Electrolyte Physiology and Departments of Medicine, Peter Bent Brigham \\ Hospital, and Harvard Medical School, Boston, Massachusetts 02115
}

\begin{abstract}
A B S T R A C T Micropuncture study was performed in 21 mildly volume-expanded Munich-Wistar rats before and during partial aortic constriction to examine the effects of endogenous prostaglandins (PG) and angiotensin II (AII) on single nephron glomerular filtration rate (SNGFR) and absolute proximal reabsorption rate (APR). Animals received either vehicle (group 1), indomethacin (group 2), or indomethacin plus saralasin (group 3). Before aortic constriction, these inhibitors were without effect on values of SNGFR and APR. In group 1 rats, reduction in mean renal arterial perfusion pressure $(\overline{\mathrm{RAP}})$ to $\sim 65 \mathrm{~mm} \mathrm{Hg}$ resulted in marked and proportional declines in SNGFR and APR. With equivalent reduction in $\overline{\mathrm{RAP}}$ in group 2 rats, however, SNGFR fell to a lesser extent and APR tended to increase slightly above preconstriction values. Indomethacin administration was therefore associated with disruption of glomerulotubular balance. In view of the roughly equivalent declines in afferent arteriolar resistance measured in groups 1 and 2, the magnitude of increase in efferent arteriolar resistance $\left(R_{E}\right)$ appeared to be of major importance in determining the observed presence or absence of glomerulotubular balance. Thus, the lesser fall in SNGFR in group 2 than in group 1 was a result of the higher value for glomerular capillary hydraulic pressure in group 2, a consequence of the higher value of $R_{E}$. The higher average value
\end{abstract}

Portions of these studies were presented at the Eastern Section Meeting of the American Federation for Clinical Research, 19 October 1979, Boston, Mass., and at the 12th Annual Meeting of the American Society of Nephrology, 20 November 1979, Boston, Mass., and were published in abstract form 1979 (Clin. Res. 27: 600A., American Society of Nephrology. 12: 51A).

Received for publication 22 October 1979 and in revised form 3 January 1980. for APR during reduced $\overline{\mathrm{RAP}}$ in group 2 than in group 1 is also attributable to this pronounced rise in $R_{E}$, the effect of which was to augment the net reabsorptive pressure both by favoring higher postglomerular oncotic pressure and lower downstream (peritubular capillary) hydraulic pressure. Since intrarenal release of AII is enhanced when $\overline{\mathrm{RAP}}$ declines, and because AII is known to raise $R_{E}$ selectively, it is likely that endogenous AII brought about the marked increase in $R_{E}$ in group 2 , which was readily demonstrable only in indomethacin-treated rats, presumably because endogenous PG synthesis was suppressed.

In keeping with this conclusion, when the action of endogenous AII was inhibited by saralasin in group 3 rats, reduction in $\overline{\mathrm{RAP}}$ failed to induce a rise in $\mathrm{R}_{\mathrm{F}}$, so that net filtration and reabsorption pressures again declined proportionally, as did SNGFR and APR. The present evidence therefore suggests that glomerulotubular balance is influenced to an important extent by the prevailing vasomotor tone of the efferent arteriole.

\section{INTRODUCTION}

As with fluid movement across extrarenal capillary beds, rates of filtration and absorption of fluid across renal glomerular and peritubular capillaries are governed by local imbalances in transcapillary hydraulic and colloid osmotic pressures (the so-called Starling forces) (1-17). Moreover, changes in glomerular filtration rate (GFR) are regularly accompanied by directionally similar and roughly proportional changes in the absolute rate of proximal tubule fluid reabsorption (APR). This phenomenon of glomerulotubular balance has been shown to depend, at least in part, on simultaneous and complementary adjustments in glomerular and peritubular transcapillary Starling forces $(3,5-7,10,17-20)$. 
It is uncertain at present whether adjustments in transcapillary fluid exchange across the series-linked glomerular and peritubular capillary networks are mediated by intrarenal or extrarenal mechanisms. For example, partial aortic constriction and renal venous occlusion, maneuvers commonly used to elicit changes in GFR and APR, are known to stimulate intrarenal angiotensin II and prostaglandin synthesis and release (21-28); both hormone systems are capable of altering glomerular and postglomerular Starling forces substantially $(18-20,29-34)$. The present study was therefore designed to evaluate the roles played by these endogenous renal vasoactive substances in mediating the close coupling between GFR and APR that occurs in response to partial aortic constriction in the Munich-Wistar rat.

\section{GLOSSARY OF SYMBOLS}

\begin{tabular}{|c|c|}
\hline AII & Angiotensin II \\
\hline APR & Absolute proximal reabsorption, $\mathrm{nl} / \mathrm{min}$ \\
\hline C & Protein concentration, g/dl \\
\hline GFR & Whole kidney glomerular filtration rate, $\mathrm{ml} / \mathrm{min}$ \\
\hline Hct & Blood hematocrit in femoral artery, vol\% \\
\hline $\mathbf{K}_{\mathrm{f}}$ & $\begin{array}{l}\text { Glomerular capillary ultrafiltration coefficient, } \\
\mathrm{nl} /(\mathrm{s} \cdot \mathrm{mm} \mathrm{Hg})\end{array}$ \\
\hline $\mathrm{K}_{\mathrm{r}}$ & $\begin{array}{l}\text { Peritubular capillary reabsorption coefficient, } \\
\mathrm{nl} /(\mathrm{s} \cdot \mathrm{mm} \mathrm{Hg})\end{array}$ \\
\hline $\mathbf{P}$ & Hydraulic pressure, $\mathrm{mm} \mathrm{Hg}$ \\
\hline PG & Prostaglandins \\
\hline $\mathrm{P}_{\mathrm{r}}$ & $\begin{array}{l}\text { Local net peritubular transcapillary reabsorptive } \\
\text { pressure, } \mathrm{mm} \mathrm{Hg}\end{array}$ \\
\hline P 113 & Saralasin, or $\left[\mathrm{Sar}^{1}, \mathrm{Val}^{5}, \mathrm{Ala}^{8}\right]-\mathrm{A}$ II \\
\hline$\Delta \mathrm{P}$ & $\begin{array}{l}\text { Glomerular or peritubular transcapillary hydraulic } \\
\text { pressure difference, } \mathrm{P}_{\mathrm{GC}}-\mathrm{P}_{\mathrm{T}} \text { or } \mathrm{P}_{\mathrm{C}}-\mathrm{P}_{\mathrm{I}}, \mathrm{mm} \mathrm{Hg}\end{array}$ \\
\hline$\Pi$ & Colloid osmotic pressure, $\mathrm{mm} \mathrm{Hg}$ \\
\hline$\Delta \Pi$ & $\begin{array}{l}\text { Peritubular transcapillary colloid osmotic pressure } \\
\text { difference, } \Pi_{C}-\Pi_{I}, \mathrm{~mm} \mathrm{Hg}\end{array}$ \\
\hline Q & Plasma flow rate, $\mathrm{nl} / \mathrm{min}$ \\
\hline$\underline{\mathbf{R}}$ & Resistance to blood flow, dyne $\cdot \mathrm{s} \cdot \mathrm{cm}^{-5}$ \\
\hline$\overline{\mathrm{RAP}}$ & Mean left renal arterial perfusion pressure, $\mathrm{mm} \mathrm{Hg}$ \\
\hline SNFF & Single nephron filtration fraction \\
\hline SNGFR & Single nephron glomerular filtration rate, $\mathrm{nl} / \mathrm{min}$ \\
\hline$(\mathrm{TF} / \mathrm{P})_{\mathrm{In}}$ & $\begin{array}{l}\text { Late proximal tubule fluid-to-plasma inulin con- } \\
\text { centration ratio }\end{array}$ \\
\hline
\end{tabular}

\section{Superscript}

Mean value

\section{Subscript}

$\begin{array}{ll}\text { A } & \text { Afferent arteriole } \\ \text { C } & \text { Peritubular capillary } \\ \text { C' } & \text { Distal-most surface branches of peritubular capillaries } \\ \text { E } & \text { Efferent arteriole } \\ \text { GC } & \text { Glomerular capillary } \\ \text { I } & \text { Cortical interstitium } \\ \text { T } & \text { Proximal tubule }\end{array}$

\section{METHODS}

Experiments were performed in 21 adult male Munich-Wistar rats weighing 288-366 $\mathrm{g}$ and allowed free access to standard rat pellet chow and water before study. Rats were anesthetized with Inactin (100 mg/kg, i p.; Byk Gulden Lomberg Chemische Fabrik GmbH, Konstanz; West Germany) and prepared for micropuncture as described previously (35). To restore plasma losses during surgical preparation and micropuncture study (35), each rat received an intravenous infusion of homologous rat plasma (obtained at the time of micropuncture by exsanguination of a littermate) at the rate of $10 \mathrm{ml} / \mathrm{kg}$ per $\mathrm{h}$ for the first $45 \mathrm{~min}$, followed by reduction in infusion rate to $1.5 \mathrm{ml} / \mathrm{kg}$ per $h$ for the remainder of each experiment. Each rat was also given an intravenous infusion of a volume of isotonic saline equal to $3 \%$ body wt administered in a period of $45 \mathrm{~min}$. The infusion rate was then reduced to $10 \mathrm{ml} / \mathrm{kg}$ per $\mathrm{h}$ for the remainder of the experiment. An intravenous infusion of inulin in $0.9 \% \mathrm{NaCl}(1.2 \mathrm{ml} / \mathrm{h})$ was begun $60 \mathrm{~min}$ before micropuncture study, resulting in final plasma inulin concentrations of about $100 \mathrm{mg} / \mathrm{dl}$. Mean left renal arterial perfusion pressure $(\overline{\mathrm{RAP}})$ was monitored via a catheter placed in the left femoral artery, using an electronic transducer (model P23Db, Statham Instruments Inc., Oxnard, Calif.) connected to a direct-writing recorder (model 7754A, Hewlett-Packard Co., Palo Alto, Calif.). Late surface convolutions of proximal tubules were located by observing the passage of lissamine green dye which was injected rapidly $(0.05 \mathrm{ml}$ of a $5 \%$ solution $)$ into the right jugular vein catheter.

Preconstriction period. In groups $2(n=7$ rats) and $3(n$ $=7$ rats), suppression of prostaglandin (PG) biosynthesis was achieved by adding indomethacin to the inulin solution to deliver $3.5 \mathrm{mg} / \mathrm{kg}$ per $\mathrm{h}$ throughout the duration of each experiment. In group 3 , saralasin (P 113), a competitive angiotensin II antagonist, was also infused at the rate of $0.3 \mathrm{mg} / \mathrm{kg}$ per $\mathrm{h}$ throughout each experiment. In group 1 ( $n=7$ rats), vehicle alone was substituted for these inhibitors. The following micropuncture measurements and collections were carried out in random order in the initial or preconstriction period in all three groups. Exactly timed (1-2-min) samples of fluid were collected from surface late proximal convolutions from each of two of three nephrons for determination of flow rate and inulin concentration. These measurements permit calculation of tubule fluid-to-plasma inulin concentration ratios, $(\mathrm{TF} / \mathrm{P})_{\text {In }}$, and single nephron glomerular filtration (SNGFR) and APR rates, as described previously (17). Coincidental with these tubule fluid collections, two or three samples of femoral arterial blood were obtained for determination of systemic arterial hematocrit (Hct) and plasma concentrations of total protein and inulin. In addition, two or three samples of urine from the left kidney were collected for determination of flow rate and inulin concentration, and calculation of total (left) kidney GFR. For these urine collections, indwelling ureteral polyethylene catheters (PE-50 or PE-10) were used.

Protein concentrations of plasma entering glomerular $\left(C_{A}\right)$ and peritubular capillaries $\left(C_{E}\right)$ were determined by analyzing femoral arterial and surface efferent arteriolar blood plasmas, respectively. These inlet estimates of pre- and postglomerular plasma protein concentration also permit calculation of single nephron filtration fraction (SNFF) and initial glomerular $\left(Q_{A}\right)$ and peritubular $\left(Q_{E}\right)$ capillary plasma flow rates, using equations described previously (17). Colloid osmotic pressures in afferent $\left(\Pi_{A}\right)$ and efferent $\left(\Pi_{E}\right)$ arteriolar plasmas were estimated from values of $C_{A}$ and $C_{E}(17)$. In addition, renal lymph was obtained by inserting micropipettes (outer tip diameters of $\sim 25 \mu \mathrm{m}$ ) into intact renal hilar lymph vessels. Because renal lymph originates primarily in the renal cortex (36-38), interstitial colloid osmotic pressure $\left(\Pi_{1}\right)$ was estimated from the value of protein concentration measured in this lymph fluid (17).

Capillary and tubule hydraulic pressures were measured with a continuous recording, servo-null micropipette transducer system (model 3, Instrumentation for Physiology and 
TABLE I

Mean Values for Whole Kidney and Single Nephron GFR and the Determinants of Filtration

\begin{tabular}{|c|c|c|c|c|c|c|c|c|c|c|c|}
\hline & $\overline{\mathrm{RAP}}$ & Het & $\mathrm{C}_{\mathrm{A}}$ & GFR & $Q_{A}$ & SNFF & SNGFR & $\overline{\mathrm{P}}_{\mathrm{GC}}$ & $\mathrm{P}_{\mathrm{T}}$ & $\overline{\mathrm{AP}}$ & $\mathrm{K}_{\mathrm{f}}$ \\
\hline & $m m \mathrm{Hg}$ & vol \% & g/dl & $\mathrm{ml} / \mathrm{min}$ & nl/min & & $n l / m i n$ & & $m m \mathrm{Hg}$ & & $\begin{array}{c}n l l \\
(s \cdot m m \mathrm{Hg})\end{array}$ \\
\hline \multicolumn{12}{|l|}{$\begin{array}{c}\text { Group } 1 \text { (vehicle, } \\
n=7 \text { rats) }\end{array}$} \\
\hline \multirow[t]{2}{*}{ Preconstriction } & 114 & 44.5 & 4.9 & 1.39 & 159 & 0.38 & 57.9 & 50.5 & 17.4 & 33.1 & 0.108 \\
\hline & \pm 4 & 0.8 & 0.1 & 0.05 & 7 & 0.01 & 2.0 & 0.7 & 0.9 & 1.0 & 0.006 \\
\hline \multirow[t]{2}{*}{ Aortic constriction } & 66 & 42.7 & 4.5 & 0.98 & 116 & 0.35 & 39.8 & 44.2 & 15.0 & 29.2 & 0.076 \\
\hline & 1 & 1.0 & 0.1 & 0.09 & 8 & 0.02 & 2.5 & 0.9 & 0.5 & 0.7 & 0.008 \\
\hline$P$ value* & $<0.001$ & $<0.001$ & $<0.001$ & $<0.005$ & $<0.001$ & $<0.005$ & $<0.001$ & $<0.001$ & $<0.05$ & $<0.001$ & $<0.025$ \\
\hline \multicolumn{12}{|c|}{$\begin{array}{l}\text { Group } 2 \text { (indomethacin, } \\
\quad n=7 \text { rats) }\end{array}$} \\
\hline \multirow[t]{2}{*}{ Preconstriction } & 113 & 44.1 & 5.0 & 1.29 & 148 & 0.37 & 54.4 & 50.7 & 16.0 & 34.7 & 0.102 \\
\hline & 3 & 0.6 & 0.1 & 0.08 & 16 & 0.01 & 5.0 & 1.3 & 0.7 & 1.6 & 0.018 \\
\hline \multirow[t]{2}{*}{ Aortic constriction } & 67 & 42.9 & 4.6 & 0.98 & 102 & 0.40 & 41.6 & 49.6 & 13.7 & 35.8 & 0.050 \\
\hline & 2 & 0.8 & 0.1 & 0.10 & 9 & 0.02 & 4.1 & 1.0 & 0.6 & 1.8 & 0.005 \\
\hline$P$ value* & $<0.001$ & $<0.001$ & $<0.001$ & $<0.01$ & $<0.005$ & $<0.05$ & $<0.01$ & $>0.20$ & $<0.025$ & $>0.20$ & $<0.05$ \\
\hline \multicolumn{12}{|c|}{$\begin{array}{l}\text { Group } 3 \text { (indomethacin } \\
+ \text { P } 113, n=7 \text { rats) }\end{array}$} \\
\hline \multirow[t]{2}{*}{ Preconstriction } & 112 & 45.2 & 4.9 & 1.22 & 157 & 0.37 & 58.4 & 49.8 & 15.8 & 33.9 & 0.095 \\
\hline & 1 & 0.5 & 0.1 & 0.07 & 5 & 0.01 & 1.6 & 0.9 & 1.1 & 0.5 & 0.008 \\
\hline \multirow[t]{2}{*}{ Aortic constriction } & 66 & 43.2 & 4.5 & 0.84 & 118 & 0.31 & 36.2 & 41.3 & 14.8 & 26.5 & 0.091 \\
\hline & 1 & 0.4 & 0.1 & 0.09 & 9 & 0.02 & 1.5 & 0.6 & 0.9 & 0.9 & 0.015 \\
\hline$P$ value* & $<0.001$ & $<0.001$ & $<0.001$ & $<0.001$ & $<0.001$ & $<0.005$ & $<0.001$ & $<0.001$ & $<0.005$ & $<0.001$ & $>0.50$ \\
\hline$P$ value $\ddagger$ & $>0.50$ & $>0.50$ & $>0.50$ & $>0.50$ & $>0.50$ & $<0.005$ & $>0.20$ & $<0.01$ & $>0.50$ & $<0.001$ & $>0.40$ \\
\hline$P$ value $\S$ & $>0.50$ & $>0.50$ & $>0.50$ & $>0.50$ & $>0.50$ & $<0.001$ & $<0.025$ & $<0.001$ & $>0.10$ & $<0.001$ & $<0.05$ \\
\hline$P$ valuef & $>0.50$ & $>0.50$ & $>0.50$ & $>0.50$ & $>0.50$ & $>0.10$ & $>0.10$ & $>0.20$ & $>0.10$ & $>0.40$ & $>0.05$ \\
\hline
\end{tabular}

Values expressed as mean \pm 1 SE. $\overline{\Delta \mathrm{P}}$ denotes mean glomerular transcapillary hydraulic pressure difference.

* Calculated from paired data in each rat by Student's $t$ test.

Calculated from unpaired data for the changes:

$\$$ group 1 vs. group 2 ;

$\$$ group 2 vs. group 3;

I group 3 vs. group 1 .

Medicine, San Diego, Calif.). Micropipettes with outer tip diameters of $2-3 \mu \mathrm{m}$ and containing $2.0 \mathrm{M} \mathrm{NaCl}$ were used. Hydraulic output from the servo-null system was coupled electronically to a second channel of the Hewlett-Packard recorder by means of a pressure transducer. Direct measurements of time-averaged hydraulic pressures in single glomerular capillaries $\left(\overline{\mathbf{P}}_{\mathrm{GC}}\right)$, proximal tubules $\left(\mathrm{P}_{\mathrm{T}}\right)$, efferent arterioles $\left(\mathrm{P}_{\mathrm{E}}\right)$, and the distal-most surface branches of peritubular capillaries $\left(\mathrm{P}_{\mathrm{C}}{ }^{1}\right)$ were recorded in each rat. Using the same device, subcapsular space hydraulic pressure was also measured and the values obtained were taken to reflect renal cortical interstitial hydraulic pressure $\left(\mathrm{P}_{\mathrm{I}}\right){ }^{1}$

Partial aortic constriction period. Upon completion of the control micropuncture measurements outlined above, $\overline{\mathrm{RAP}}$

${ }^{1}$ Because the mathematical model for peritubular transcapillary fluid exchange recently developed by us and others for rat deals with the data from superficial cortical nephrons primarily, subcapsular hydraulic pressure has been exclusively used in assessing local interstitial hydraulic pressure in this area. was reduced in all rats of each group to $\sim 65 \mathrm{~mm} \mathrm{Hg}$, by means of partial constriction of the abdominal aorta. Partial aortic constriction was achieved by applying tension to a 000 silk ligature encircling the abdominal aorta between the origins of the renal arteries. $\overline{\mathrm{RAP}}$ was maintained at this level for the remainder of each experiment. 20 min later, measurements and collections specified above were repeated, again in random order. Recollections of late proximal tubule fluid were obtained from previous puncture sites of the same tubules studied in the preconstriction period. During the second study period, vehicle (group 1), indomethacin (group 2), or indomethacin P113 (group 3) were infused at the same rates as were used in the preconstriction period.

Calculations. From the measured decline in hydraulic pressure along single afferent $\left(\overline{\mathrm{AP}}-\overline{\mathrm{P}}_{\mathrm{GC}}\right)$ and efferent $\left(\overline{\mathrm{P}}_{\mathrm{GC}}\right.$ $-P_{E}$ ) arterioles, together with the calculated blood flow rates through these vessels, it was possible to calculate resistances to blood flow offered by single afferent $\left(R_{A}\right)$ and efferent arterioles $\left(\mathbf{R}_{\mathbf{E}}\right)$, using equations described previously (39). Details of the methods for calculation of the glomerular capillary ultrafiltration coefficient $\left(K_{f}\right)$ are also given elsewhere (39).

According to the Starling relationship, the rate of peritubular 
capillary uptake of APR is given by: $A P R=K_{r} \cdot \bar{P}_{r}=K_{r} \cdot(\overline{\Delta \Pi}$ $-\overline{\Delta \mathrm{P}})=\mathrm{K}_{\mathrm{r}} \cdot\left[\left(\bar{\Pi}_{\mathrm{C}}-\Pi_{\mathrm{I}}\right)-\left(\overline{\mathbf{P}}_{\mathrm{C}}-\mathrm{P}_{\mathrm{I}}\right)\right]$; where $\mathrm{K}_{\mathrm{r}}$ and $\overline{\mathrm{P}}_{\mathrm{r}}$ represent peritubular capillary reabsorption coefficient and mean net reabsorptive pressure, respectively; $\overline{\Delta \Pi}$ and $\overline{\Delta \mathrm{P}}$ are the mean peritubular transcapillary oncotic and hydraulic pressure differences; $\bar{\Pi}_{C}$ and $\overline{\mathrm{P}}_{C}$ are the mean peritubular intracapillary oncotic and hydraulic pressures; and $\Pi_{1}$ and $P_{I}$ are the corresponding pressures in the surrounding cortical interstitium. $\overline{\mathrm{P}}_{\mathrm{C}}$ was estimated from the expression: $\left(\mathrm{P}_{\mathrm{E}}+\mathrm{P}_{\mathrm{C}}{ }^{1}\right) / 2 .^{2}$

$\mathrm{K}_{\mathrm{r}}$ and $\overline{\mathrm{P}}_{\mathrm{r}}$, and thus $\overline{\Delta \Pi}$ and $\bar{\Pi}_{\mathrm{C}}$ were calculated with a differential equation that gives the rate of change of protein concentration with distance along an idealized peritubular capillary. This equation, together with its derivation and the method for its solution, is discussed in detail elsewhere $(11,12)$.

\section{RESULTS}

Preconstriction period. Mean values for $\overline{\mathrm{RAP}}$, blood hematocrit in femoral artery (Hct) and a number of other measures of plasma and urine composition and single nephron function in groups $1-3$ are summarized in Table I. Preconstriction values for $\overline{\mathrm{RAP}}, \mathrm{Hct}, \mathrm{C}_{\mathrm{A}}$, and whole kidney GFR were essentially identical in all groups. As also shown in Table I, preconstriction values for SNGFR; plasma flow rates, afferent arteriole $\left(Q_{A}\right)$, SNFF; $\overline{\mathrm{P}}_{\mathrm{GC}} ; \mathrm{P}_{\mathrm{T}} ; \overline{\Delta \mathrm{P}}\left(=\overline{\mathrm{P}}_{\mathrm{GC}}-\mathrm{P}_{\mathrm{T}}\right)$ and $\mathrm{K}_{\mathrm{f}}$ were likewise similar in each group.

Mean values for $(\mathrm{TF} / \mathrm{P})_{\mathrm{In}}, \mathrm{APR}$, and the various determinants of peritubular capillary uptake of APR obtained in the preconstriction period in these three groups of rats are given in Table II. As shown, values for $(\mathrm{TF} / \mathrm{P})_{\text {In }}$ and APR measured in the preconstriction period were similar in groups 1-3. Likewise, during this initial control period, average values for intravascular oncotic pressure at the beginning of the peritubular capillary network, $\Pi_{E}$, were similar among the three groups, as were values for initial efferent peritubular capillary plasma flow rate $\left(Q_{E}\right)$. Insofar as $\bar{\Pi}_{C}$ is determined by $\Pi_{E}$ and $Q_{E}$ and by the degree of subsequent dilution of peritubular capillary plasma protein concentration by reabsorbate (i.e., APR), ${ }^{3}$ the similar values of $A P R, \Pi_{E}$, and $Q_{E}$ in the

\footnotetext{
${ }^{2}$ Values for hydraulic pressure were also measured in first order branches of surface efferent arterioles, vessels approximately equidistant between efferent arterioles (where $P_{E}$ was measured) and terminal peritubular capillaries (where $P_{C}{ }^{1}$ was measured). The resulting pressures were roughly midway between values for $P_{E}$ and $P_{C}{ }^{1}$, justifying use of the equation given.

${ }^{3}$ Because distal convoluted tubules of superficial nephrons are also perfused with surface peritubular capillaries, APR undoubtedly underestimates true peritubular capillary fluid uptake in absolute terms. In view of the small amount of reabsorption by cortical distal convolutions $(\sim 5 \%$ of filtered load), however, the magnitude of this underestimation is quite small. Moreover, fewer than half of all superficial nephrons have distal convolutions on the renal cortical surface. We have therefore chosen, as have others $(12,40)$ to neglect this distal reabsorptive component, which we estimate to be $<1.5 \mathrm{nl} / \mathrm{min}$, compared with measured APR values, which always averaged $>16 \mathrm{nl} / \mathrm{min}$, and usually $>23 \mathrm{nl} / \mathrm{min}$.
}

preconstriction period in groups 1-3 led to similar values for $\bar{\Pi}_{c}$ in each group (Table II). Because mean values for interstitial oncotic pressure, $\Pi_{\mathrm{I}}$, were also essentially identical in the initial period in each group, mean peritubular transcapillary oncotic pressure difference, $\overline{\Delta \Pi}$, which is given by $\bar{\Pi}_{c}-\Pi_{l}$, was also similar among groups. Likewise, hydraulic pressures measured at $\mathrm{P}_{\mathrm{E}}$ and $\mathrm{P}_{\mathrm{C}}{ }^{1}$ along the peritubular capillary network, and thus $\bar{P}_{C}$, were also essentially identical in the initial period in the three groups. Finally, because mean values for $P_{I}$ were nearly the same in all groups, $\overline{\Delta \mathrm{P}}\left(=\overline{\mathrm{P}}_{\mathrm{C}}-\mathrm{P}_{\mathrm{I}}\right)$ was also numerically similar in the initial period in these three groups. Collectively, therefore, $\overline{\mathrm{P}}_{\mathrm{r}}$, which is given by $\overline{\Delta \Pi}-\overline{\Delta \mathrm{P}}$, averaged very nearly the same in the preconstriction period in each group, as shown in Table II. Moreover, since mean values for $A P R$ and $\bar{P}_{r}$ were similar in this period for all groups, average values for $\mathrm{K}_{\mathrm{r}}$ also were similar (Table II). Finally, as shown in Table II, values for $R_{A}$ and $R_{E}$ in the preconstriction period were statistically similar in all groups.

Partial aortic constriction period. Mean values for a number of indices of whole kidney and single nephron function measured during reduced $\overline{\mathrm{RAP}}$ are also shown in Tables I and II and Figs. 1 and 2. Equivalent reductions in $\overline{\text { RAP }}$ were achieved in groups $1-3$ (Table I). Values for Hct and $C_{A}$ fell slightly but similarly in all three groups, reflecting the continued infusion of colloid-free solutions. With reduction in $\overline{\mathrm{RAP}}$, GFR decreased significantly in each group. Likewise, values for $Q_{A}$ fell significantly in each group, again indicating that the magnitude of the reduction in $\overline{\mathrm{RAP}}$ induced by partial aortic constriction was beyond the autoregulatory range. Although reductions in $\overline{\mathrm{RAP}}$ and $\mathrm{Q}_{\mathrm{A}}$ were essentially equivalent in magnitude in each group, values for SNFF increased significantly with blockade of PG synthesis in group 2 whereas SNFF fell significantly in groups 1 and 3 (Table I). Given the similar reductions in $Q_{A}$ among groups, and the increase in SNFF only in group 2 , it follows that the reductions in SNGFR measured in group 2 were, on average, less than in the other two groups studied (Table I and Fig. 1). As with the relatively high values for SNFF and SNGFR in group $2, \overline{\mathrm{P}}_{\mathrm{GC}}$ values in group 2 exceeded those in groups 1 and 3 (Table I and Fig. 2). As shown in Table I, average values for $\mathrm{P}_{\mathrm{T}}$ fell slightly and equivalently in all three groups. Therefore, $\overline{\Delta \mathrm{P}}\left(=\overline{\mathrm{P}}_{\mathrm{GC}}-\mathrm{P}_{\mathrm{T}}\right)$ fell significantly only in groups 1 and 3 (Table I). Finally, as also shown in Table I, a significant reduction of $K_{f}$ was observed with aortic constriction in group 1 animals. Whereas infusion of the PG synthetase inhibitor failed to affect this decline in $K_{f}$ with aortic constriction (group 2), addition of the AII antagonist to group 3 rats prevented this fall in $K_{f}$. In groups 1 and 3, therefore, GFR and SNGFR each fell with partial aortic constriction on average by $\sim 30 \%$, due primarily to the concomitant average de- 


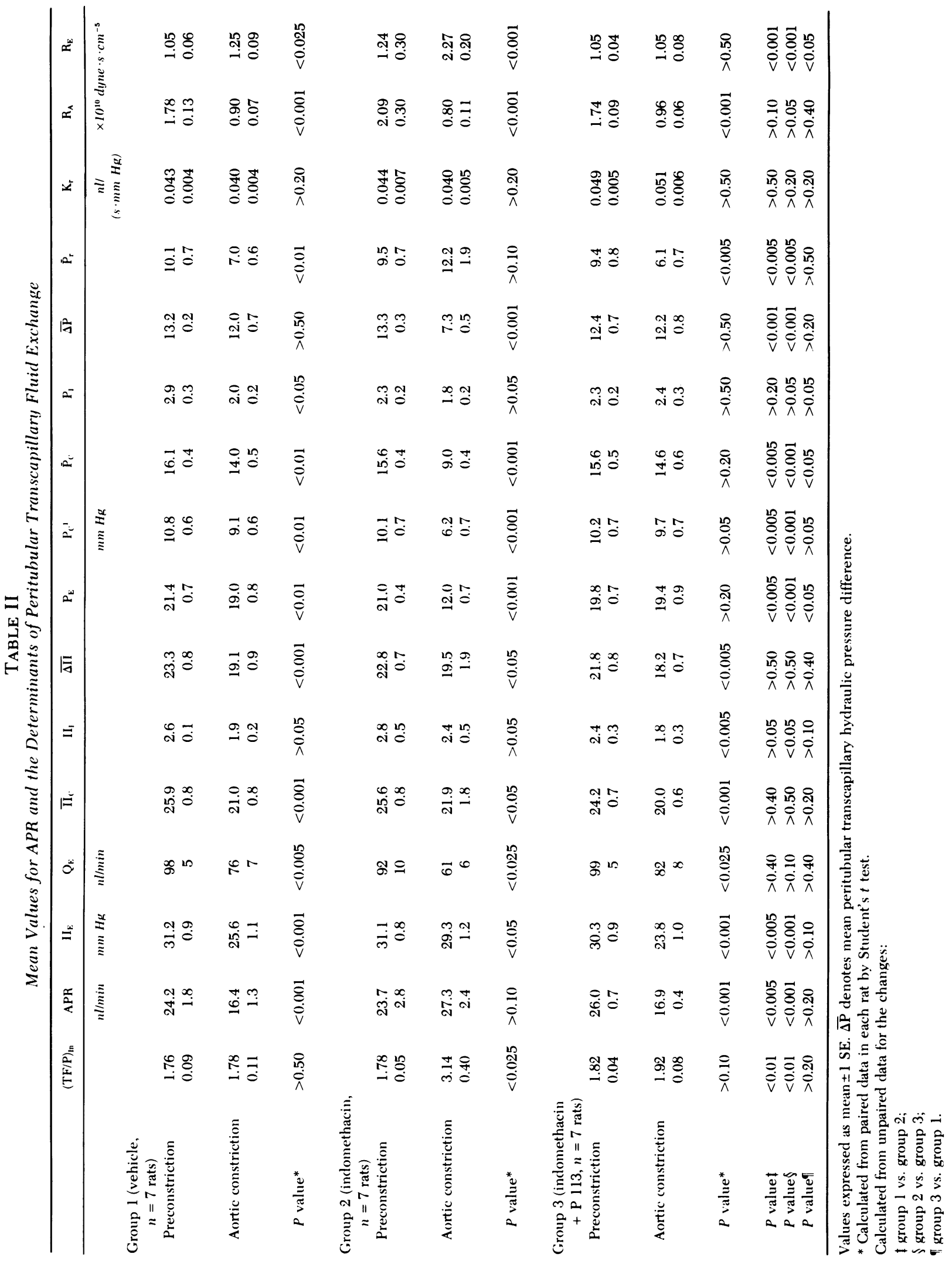



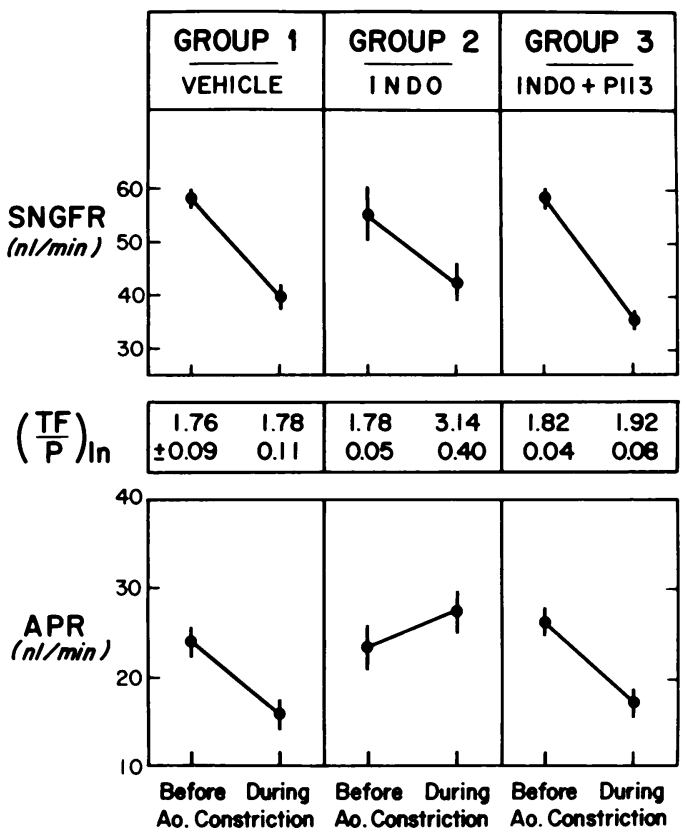

Figure 1 Summary of changes in SNGFR, $(\mathrm{TF} / \mathrm{P})_{\text {In }}$, and APR in response to partial aortic (Ao.) constriction in vehicle(group 1), indomethacin (INDO)- (group 2), and indometha(in plus P 113-(group 3) treated animals. Seven rats were in each group. Values are expressed as mean $\pm 1 \mathrm{SE}$.

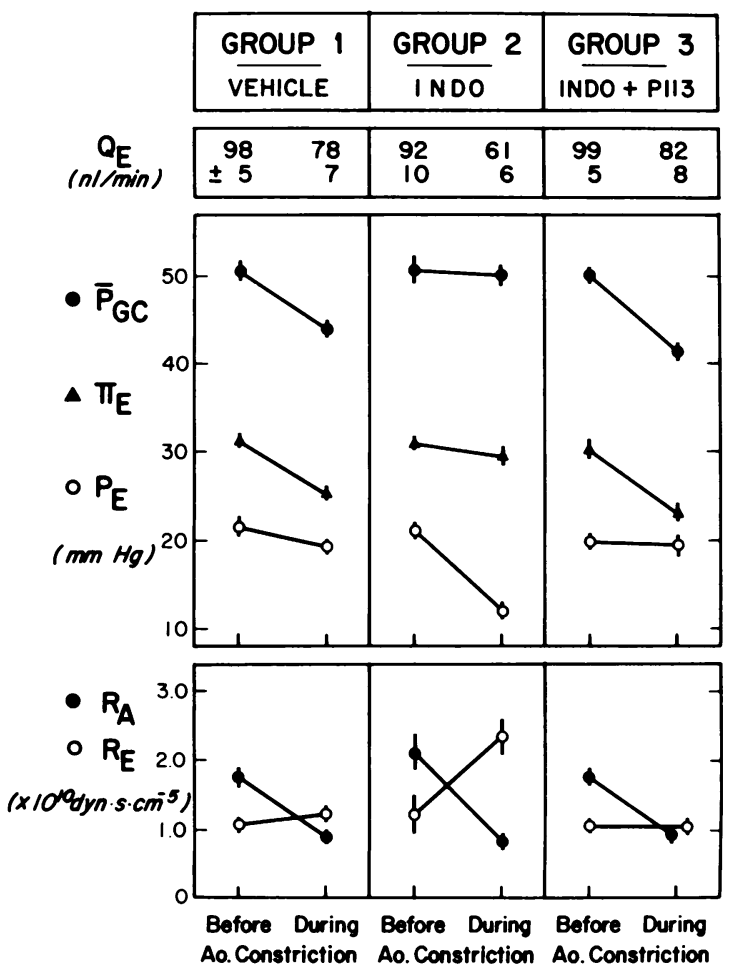

FIGURE 2 Summary of changes in single nephron pressures, flow, and resistance in response to partial aortic constriction in groups 1-3. Values are expressed as mean \pm 1 SE. clines in $Q_{A}$ and $\overline{\Delta P}$. Although $K_{f}$ also fell in group 1 rats, this change did not prove to be of significance because animals remained near filtration pressure equilibrium. In group $3, \mathrm{~K}_{\mathrm{f}}$ remained unchanged with aortic constriction. Despite declines in $K_{f}$ and $Q_{A}$ in group 2 animals which exceeded those in groups 1 and 3 , values for GFR and SNGFR fell to a lesser extent in group 2 than in group 1 or 3 , owing to the lack of decline in $\overline{\Delta P}$. As noted below and in Table II, the more pronounced increase in $R_{E}$ in group 2 than in the other groups studied accounts for the relatively higher average values for $\overline{\mathrm{P}}_{\mathrm{GC}}$ and $\overline{\Delta \mathrm{P}}$ (hence SNGFR) in group 2 .

As shown in Table II and Fig. 1, the effects of partial aortic constriction on proximal tubule fluid reabsorption and its determinants also differed in group 2 rats, relative to groups 1 and 3 . Whereas $(\mathrm{TF} / \mathrm{P})_{\text {In }}$ remained essentially constant in response to reduced $\overline{\mathrm{RAP}}$ in groups 1 and 3 , relative to preconstriction values, this measure increased markedly in group 2 , on average by nearly $80 \%$ (Table II). With reductions in SNGFR, therefore, APR fell proportionately in groups 1 and 3 but remained statistically unchanged from preconstriction levels (and numerically higher) in group 2 . In the presence of the prostaglandin synthetase inhibitor, therefore, APR failed to decline with aortic constriction in group 2, thereby disrupting the nearly perfect glomerulotubular balance observed in groups 1 and 3 .

Mean values for the various determinants of APR measured in each group during partial aortic constriction are shown in Table II and Fig. 2. In association with significant reductions in APR in groups 1 and 3, $C_{E}$ and $\Pi_{E}$ also fell significantly, reflecting significant declines both in $\mathrm{C}_{\mathrm{A}}$ and SNFF. In group 2, however, the increase in SNFF nearly offset the concomitant decline in $C_{A}$ so that $\Pi_{E}$ fell only slightly (Table II and Fig. 2). Nevertheless, since average values for $Q_{\mathrm{E}}$ and APR were least and most, respectively, in group 2 , relative to the other groups, values for $\bar{\Pi}_{c}$ proved to be essentially identical among the three groups studied (Table II). Finally, insofar as the reductions in $\Pi_{1}$ seen in all three groups were numerically trivial, values for $\overline{\Delta \Pi}$ were also essentially equal in the aortic constriction period in all three groups (Table II).

The $\Delta \mathrm{P}$ pattern seen in response to partial aortic constriction in group 2 rats differed from that dispalyed by groups 1 and 3 . Values for $P_{E}$ declined only slightly in groups 1 and 3 , but fell markedly in group 2 , as shown in Table II and Fig. 2. With aortic constriction, therefore, the hydraulic pressure drop along the efferent arteriole (i.e., $\overline{\mathrm{P}}_{\mathrm{GC}}-\mathrm{P}_{\mathrm{E}}$ ) was much greater in group 2 $(\sim 38 \mathrm{~mm} \mathrm{Hg})$ than in groups 1 and $3(\sim 23 \mathrm{~mm} \mathrm{Hg})$. Hydraulic pressures measured at $\mathrm{P}_{C}{ }^{1}$ were also significantly lower during aortic constriction in group 2 than in groups 1 and 3 (Table II). Values for $\overline{\mathrm{P}}_{\mathrm{C}}$ therefore declined markedly in group 2 , to levels significantly lower than in the other two groups studied. Because of 
numerically very small changes in $\mathrm{P}_{\mathrm{I}}$ induced by aortic constriction in all three groups $\overline{\Delta \mathrm{P}}$ declined only in group 2 but remained essentially constant in groups 1 and 3. Therefore, in groups 1 and 3, given the relative constancy of $\overline{\Delta \mathrm{P}}$ for the peritubular capillary network between preconstriction and aortic constriction periods, the significant average reductions in $\overline{\Delta \Pi}$ led to significant declines in $\bar{P}_{\mathrm{r}}$ (Table II). In group 2 rats, however, the greater average decline in $\overline{\Delta \mathrm{P}}$ than in $\overline{\Delta \Pi}$ with aortic constriction resulted in a slight increase in $\overline{\mathrm{P}}_{\mathrm{r}}$. Given the proportional reductions of APR and $\bar{P}_{r}$ with aortic constriction in groups 1 and 3 , calculated values for $K_{r}$ remained essentially unchanged, on the average, in these two groups, as shown in Table II. $K_{r}$ also remained unchanged on average in group 2 , reflecting, in this case, small but insignificant increases in both APR and $\bar{P}_{\mathrm{r}}$.

The average declines in $R_{A}$ in response to aortic constriction were equivalent in all three groups (Table II and Fig. 2). By contrast, $R_{E}$ tended to change little, on average, with aortic constriction in groups 1 and 3 , but increased markedly in group 2 , reflecting the distinctly higher and lower average values for $\overline{\mathrm{P}}_{\mathrm{GC}}$ and $\mathrm{P}_{\mathrm{E}}$, respectively, and the greater average decline in $Q_{E}$, relative to the other groups studied.

\section{DISCUSSION}

In the preconstriction period of this study, infusion of the PG synthetase inhibitor, indomethacin, whether alone (group 2) or in combination with the angiotensin II (AII) antagonist, P 113 (group 3), failed to induce detectable changes in renal hemodynamics or APR, implying that endogenous production of PG and AII was suppressed in this period, most likely because of the mild volume expansion resulting from plasma and saline infusions. With partial aortic constriction, however, the effects of these inhibitors on renal hemodynamics and APR were readily apparent, not surpris- ingly since this maneuver leads to prompt stimulation and renal release of endogenous PG and AII (21-28).

Partial aortic constriction led to a fall in vascular hydraulic pressures at every level of the renal cortical microcirculation. A summary of these pressure changes is given in Fig. 3. In group 1 rats, the average reduction in $\overline{\mathrm{RAP}}$ from 114 to $66 \mathrm{~mm} \mathrm{Hg}$ was associated with a nearly $50 \%$ reduction in $\mathrm{R}_{\mathrm{A}}$ and a concomitant small increase in $R_{E}$, on average by $\sim 20 \%$. In consequence of these arteriolar resistance changes, the decline in $\overline{\mathrm{P}}_{\mathrm{GC}}$ was proportionately less than the decline in $\overline{\mathrm{RAP}}$. The importance of $R_{E}$ in setting the levels of hydraulic pressure both upstream $\left(\overline{\mathrm{P}}_{\mathrm{GC}}\right)$ and downstream $\left(\mathrm{P}_{\mathrm{E}}\right.$ and $\mathrm{P}_{\mathrm{C}}{ }^{1}$ ) to this arteriole is highlighted by the results obtained in groups 2 and 3 (Fig. 3). In the latter group, despite an aortic constriction-induced fall in $R_{A}$ similar in magnitude to that seen in group 1 , the combined infusions of indomethacin and P 113 served to abolish the small rise in $R_{E}$ seen in group 1 . This failure for $R_{E}$ to increase with aortic constriction in group 3 led to a decline in $\overline{\mathrm{P}}_{\mathrm{GC}}$ whereas the hydraulic pressure in the microvasculature distal to the efferent arteriole $\left(\mathrm{P}_{\mathrm{E}}\right.$ and $\left.\mathrm{P}_{\mathrm{C}}{ }^{1}\right)$ remained at preconstriction levels. The opposite pattern was observed in group 2 rats given indomethacin alone in that in response to aortic constriction, $\mathrm{R}_{\mathrm{E}}$ increased nearly twofold above preconstriction levels, whereas $R_{A}$ was again decreased to the same extent as that found in groups 1 and 3. The marked rise in $R_{E}$ in group 2 served to maintain $\overline{\mathrm{P}}_{\mathrm{GC}}$ at preconstriction levels but at the same time caused a marked decline in hydraulic pressure downstream to this resistor $\left(\mathrm{P}_{\mathrm{E}}\right.$ and $\left.\mathrm{P}_{\mathrm{C}}{ }^{1}\right)$.

In addition to influencing hydraulic pressures in upstream and downstream capillaries, the pronounced rise in $\mathrm{R}_{\mathrm{E}}$ during aortic constriction in indomethacintreated rats (group 2) also led to profound effects on oncotic forces along the glomerular and peritubular capillary networks. Thus, in contrast with the fall in
GROUP I : VEHICLE

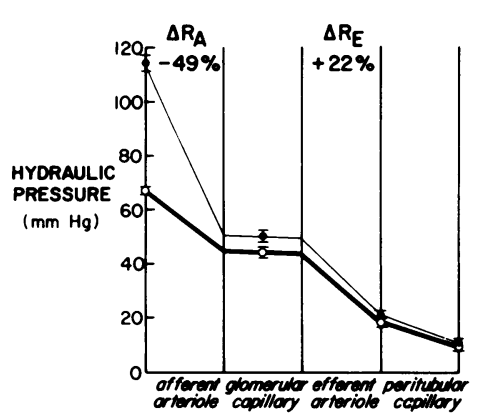

GROUP 2: INDO

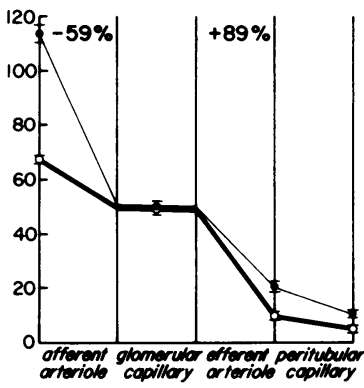

GROUP 3 : INDO+PII3

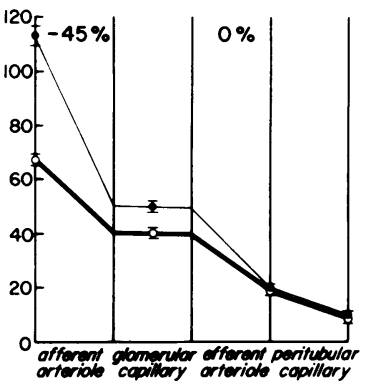

FIgURE 3 Profiles of intravascular hydraulic pressure from renal artery to terminal portion of peritubular capillaries before $(O)$ and during $(O)$ partial aortic constriction. Average changes in $R_{A}$ and $R_{E}$ are expressed as percentage of preconstriction values. 
SNFF that occurred with aortic constriction in group 1 animals (a consequence of the measured decline in $\overline{\mathrm{P}}_{\mathrm{GC}}$ ), values for SNFF rose significantly in group 2 rats, due entirely to the relatively high level of $\overline{\mathrm{P}}_{\mathrm{GC}}$ achieved in this group. As a result, $\Pi_{\mathrm{E}}$ also remained at a relatively high level in these indomethacin-treated (group 2) animals.

Fig. 4 depicts the profiles of transcapillary oncotic and hydraulic pressure differences, plotted as a function of idealized distance along the peritubular capillary network, for the preconstriction and aortic constriction periods in all three groups of rats. As indicated in the top panels of Fig. 4, values for $\Delta \Pi$ and $\Delta \mathrm{P}$ at the "afferent" or initial end of the peritubular capillary
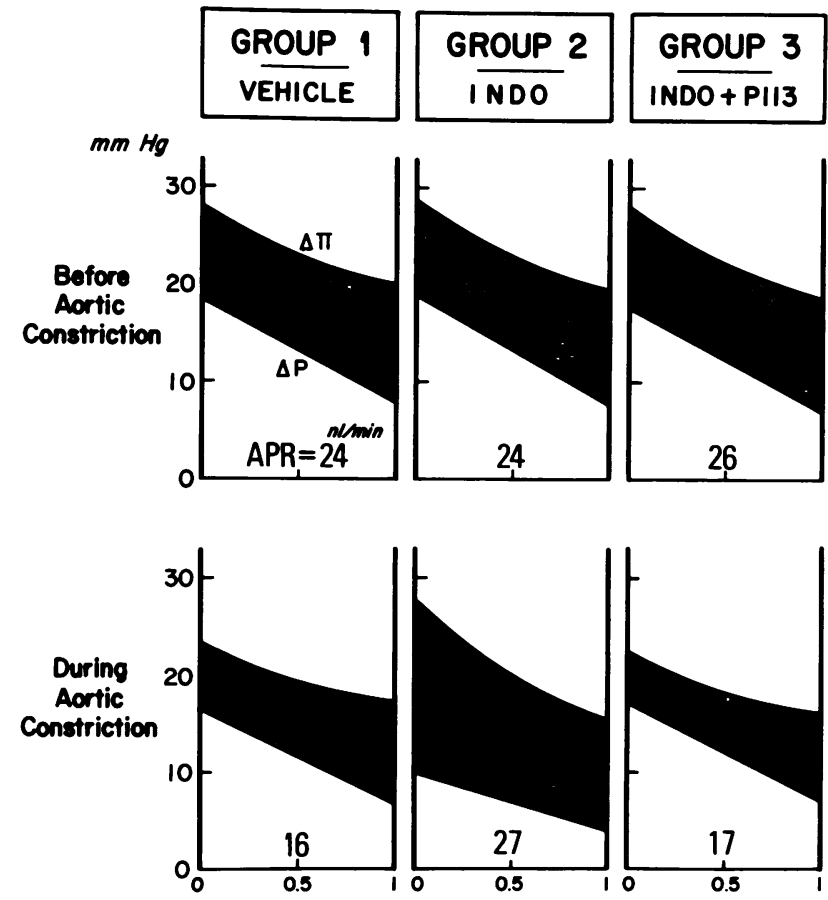

Fractional Distance along the Peritubular Capillary

Figure 4 Profiles of $\Delta \Pi\left(=\Pi_{C}-\Pi_{1}\right)$ and $\Delta P\left(=P_{C}-P_{1}\right)$ along peritubular capillaries before and during partial aortic constriction in groups $1-3$. The difference between $\Delta \Pi$ and $\Delta P$ at any given point along the capillary network represents the local net reabsorptive force. The shaded areas denote the $\Delta \Pi-\Delta \mathbf{P}$ values integrated along the entire dimensionless length of the peritubular capillary network, and yield the $\bar{P}_{r}$. Before aortic constriction (upper panels), the profiles of $\Delta \Pi$ and $\Delta \mathrm{P}$ were essentially identical in groups $1-3 ; \overline{\mathrm{P}}_{\mathrm{r}}$ was also identical in each group. Aortic constriction led to a marked decline in $\Delta \mathrm{P}$ in group 2 , but not in groups 1 or 3 . In addition, $\Delta \Pi$ fell substantially with aortic constriction in groups 1 and 3 but remained at a relatively high level in Group 2 . Overall, $\overline{\mathrm{P}}_{\mathrm{r}}$ tended to increase in group 2 in contrast to the significant decline in $\overline{\mathrm{P}}_{\mathrm{r}}$ seen with aortic constriction in groups 1 and 3 . These changes in $\bar{P}_{r}$ correlate well with the measured alterations in APR in all these groups, as shown. network were identical during the preconstriction period in all three groups. These values for $\Delta \Pi$ and $\Delta \mathrm{P}$ declined progressively with distance along this capillary network to essentially the same extent in each group. The similar declines in each group were the result of uptake of similar volumes of reabsorbate added to equivalent initial values for $\Pi_{E}$ and $Q_{E}$. The comparable declines in $\Delta \mathrm{P}$ with distance along this capillary network for each group largely reflect similar intrinsic axial resistances to blood flow in each group. Thus, as also shown in the upper panels of Fig. 4, the area between $\Delta \Pi$ and $\Delta P$ curves, i.e., $\bar{P}_{r}$, was similar in each group. Furthermore, average values for APR were also similar among groups, as shown.

The adaptations of these $\Delta \Pi$ and $\Delta \mathrm{P}$ profiles to reduced $\overline{\mathrm{RAP}}$ are shown for each group in the bottom panels of Fig. 4. Indomethacin treatment in group 2 rats increased the $P_{r}$ at the initial end of the peritubular capillary by maintaining $\Delta \Pi$ at a relatively high level and reducing $\Delta \mathrm{P}$ at this point of the capillary. In view of the numerically trivial changes in interstitial hydraulic and oncotic pressures observed in all three groups, the high inlet and length-averaged values of $P_{r}$ in group 2 are attributable to the measured marked increase in $R_{E}$ observed in this group. By contrast, in group 1 rats, inlet $P_{r}$ values declined significantly with aortic constriction, because of the fall in the $\Delta \Pi$ value without a concomitant fall in $\Delta P$. Since this pattern prevailed throughout the subsequent length of the capillaries in group 1 animals, $\overline{\mathrm{P}}_{\mathrm{r}}$ also declined significantly with aortic constriction in this group. The fall in $\overline{\mathrm{P}}_{\mathrm{r}}$ in group 1 correlated well with the measured fall in APR; in group 2 rats, APR increased slightly, but not significantly, with aortic constriction, and also correlated well with the finding of a small but significant rise in $\bar{P}_{r}$.

These results in groups 1 and 2 suggest that some endogenous vasodilator substance(s), released in response to partial aortic constriction, modifies the magnitude of the increase in $R_{E}$ induced by partial aortic constriction. With supression of synthesis and/or release of this vasodilator substance by indomethacin (group 2 rats), the efferent arteriolar vasoconstrictor response to the reduction in $\overline{\mathrm{RAP}}$ was more pronounced than in group 1, manifested not only by the higher values for $R_{E}$ and $\bar{P}_{G C}$ but also by the lower values for $Q_{A}$ and $Q_{E}$. $\Delta \Pi$ during aortic constriction was therefore higher in group 2 than in group 1 (Fig. 4), whereas the corresponding $\Delta \mathrm{P}$ was lower, resulting in the nearly twofold higher values for both $\overline{\mathrm{P}}_{\mathrm{r}}$ and APR in group 2 than in group 1 . We presume that prostaglandins are the indomethacin-sensitive vasodilators released in response to partial aortic constriction, but no biochemical confirmation was sought in this study. In keeping with this possibility, however, exogenous infusions of prostaglandins $E_{1}$ and $I_{2}$ have been shown to decrease $R_{E}$ in the Munich-Wistar rat $(19,34)$ and Strandhoy 
et al. (41) observed significant reductions in APR during exogenous $\mathrm{PGE}_{1}$ infusion in dogs in association with a fall in filtration fraction and a rise in $P_{C}$. By contrast, $R_{E}$ rises markedly in indomethacintreated rats studied under conditions in which endogenous AII levels are believed to be elevated $(31,33)$.

To further document this latter point, we infused P 113 into indomethacin-treated animals (group 3) in the present study. As noted in Table II and Figs. 2 and 3 , with $P 113$ infusion the rise in $R_{E}$ previously seen in groups 1 and 2 was essentially abolished. This finding is taken as support for a role of endogenous AII in mediating the increased $R_{E}$ seen with aortic constriction in groups 1 and 2 . To the extent that the more striking rise in $R_{E}$ in group 2 than group 1 is the result of the absence of PG in group 2, the role of PG in group 1 appears to counterbalance the vasoconstrictor influence of AII on the efferent arteriole, the principal locus of action of AII $(18,32)$. When this counterbalancing influence of PG is lessened by indomethacin treatment, as in group 2 , the rise in $R_{E}$ (which we can now attribute mainly to AII) is much more pronounced. Whereas efferent arteriolar tone appears to be sensitive to either $\mathrm{P} 113$ or indomethacin treatment, $\mathrm{R}_{\mathrm{A}}$ was remarkably unaffected by either substance, suggesting that the decline in $\mathrm{R}_{\mathrm{A}}$ was not humorally mediated but was rather the consequence of a passive or myogenic reflex (42-45).

In consequence of the failure of $R_{E}$ to rise with aortic constriction in group 3 rats, $\overline{\mathrm{P}}_{\mathrm{GC}}$ fell significantly below preconstriction levels, whereas values for $P_{E}$ and $P_{C}{ }^{1}$ tended to remain at preconstriction values. As predicted from the decline in $\tilde{\mathrm{P}}_{\mathrm{GC}}$, we measured substantial declines in SNGFR, SNFF, and $\Pi_{\mathrm{E}}$. Comparable changes in whole kidney hemodynamics with $\mathrm{P} 113$ have been reported by others (42).

The resulting reduction in the $\Delta \Pi$ profile along the peritubular capillary network with aortic constriction in group 3 rats, in the absence of a simultaneous decline of the $\Delta \mathrm{P}$ curve led to a marked decline in $\overline{\mathrm{P}}_{\mathrm{r}}$, as shown in Fig. 4. Once again, this decline in $\overline{\mathrm{P}}_{\mathrm{r}}$ correlated well with the measured fall in APR. Indeed, as shown in Fig. 4, the addition of P 113 to indomethacin-treated rats served to restore a near normal balance between intrarenal vasoconstrictor and vasodilator forces (such as existed in group 1, but not in group 2 where a vasoconstrictor influence predominated). The change in $\overline{\mathrm{P}}_{\mathrm{r}}$ with aortic constriction was therefore essentially identical in groups 1 and 3 . Of importance, the changes in APR induced by aortic constriction were also virtually identical in groups 1 and 3 .

The present findings supplement the evidence previously reported from this and other laboratories (2-17) in support of an important role for peritubular capillary Starling forces in regulating APR and glomerulotubular balance. In addition, the present results suggest that the renin-angiotensin and prostaglandin systems play an important role in influencing APR, by virtue of their recognized and predictable actions on the renal glomerular and postglomerular microcirculations. Clearly, such a mechanism by no means excludes any possible luminal or epithelial factors that have also been proposed to contribute to overall glomerulotubular balance (46).

\section{ACKNOWLEDGMENTS}

The authors are grateful to Mrs. H. Segal for expert secretarial assistance.

These studies were supported largely by a grant from the U. S. Public Health Service (AM-19467).

\section{REFERENCES}

1. Starling, E. H. 1899. The glomerular functions of the kidney. J. Physiol. (Lond.). 24: 317-330.

2. Earley, L. E., and R. M. Friedler. 1965. The effects of combined renal vasodilation and pressor agents on renal hemodynamics and the tubular reabsorption of sodium. J. Clin. Invest. 45: 542-551.

3. Lewy, J. E., and E. E. Windhager. 1968. Peritubular control of proximal tubular fluid reabsorption in the rat kidney. Am. J. Physiol. 214: 943-954.

4. Spitzer, A., and E. E. Windhager. 1970. Effect of peritubular oncotic pressure changes on proximal fluid reabsorption. Am. J. Physiol. 218: 1188-1193.

5. Brenner, B. M., and J. L. Troy. 1971. Postglomerular vascular protein concentration: evidence for a causal role in governing fluid reabsorption and glomerulotubular balance by the renal proximal tubule. J. Clin. Invest. 50: 336-349.

6. Falchuk, K. H., B. M. Brenner, M. Tadokoro, and R. W. Berliner. 1971. Oncotic and hydrostatic pressures in peritubular capillaries and fluid reabsorption by proximal tubule. Am. J. Physiol. 220: 1427-1433.

7. Weinman, E. J., M. Kashgarian, and J. P. Hayslett. 1971. Role of peritubular protein concentration in sodium reabsorption. Am. J. Physiol. 221: 1521-1528.

8. Bank, N., H. S. Aynedjian, and T. Wada. 1972. Effect of peritubular capillary perfusion rate on proximal sodium reabsorption. Kidney Int. 1: 397-405.

9. Nizet, A. 1972. Quantitative influence of non-hormonal blood factors on the control of sodium excretion by the isolated dog kidney. Kidney Int. 1: 27-37.

10. Brenner, B. M., J. L. Troy, T. M. Daugharty, and R. M. MacInnes. 1973. Quantitative importance of changes in postglomerular colloid osmotic pressure in mediating glomerulotubular balance in the rat. J. Clin. Invest. 52: 190-197.

11. Deen, W. M., C. R. Robertson, and B. M. Brenner. 1973. A model of peritubular capillary control of isotonic fluid reabsorption by the renal proximal tubule. Biophys. $J$. 13: $340-365$.

12. Blantz, R. C., and B. J. Tucker. 1975. Determinants of peritubular capillary fluid uptake in hydropenia and saline and plasma expansion. Am. J. Physiol. 228: $1927-$ 1935.

13. Ott, C., J. A. Haas, J. L. Cuche, and F. G. Knox. 1975. Effect of increased peritubular protein concentration on proximal tubule reabsorption in the presence and absence of extracellular volume expansion. J. Clin. Invest. 55: $612-620$. 
14. Stein, J. H., N. H. Lameire, and L. E. Earley. 1978. Renal hemodynamic factors and the regulation of sodium excretion. In Physiology of Membrane Disorders. T. E. Andreoli, J. F. Hoffman, and D. D. Fanestil, editors. Plenum Medical Book Co., New York. 739-772.

15. Gilbert, B. R., T. Maack, and E. E. Windhager. 1979. Microperfusion study of the effects of colloid osmotic pressure on proximal tubular fluid reabsorption in the isolated perfused rat kidney. Fed. Proc. 38: 112. (Abstr.)

16. Quinn, M. D., and D. J. Marsh. 1979. Peritubular control of proximal tubule reabsorption in the rat. Am. J. Physiol. 236: F478-F487.

17. Ichikawa, I., and B. M. Brenner. 1979. Mechanism of inhibition of proximal tubule fluid reabsorption following exposure of the kidney to the physical effects of expansion of extracellular fluid volume. J. Clin. Invest. 64: 14661474.

18. Myers, B. D., W. M. Deen, and B. M. Brenner. 1975. Effects of norepinephrine and angiotensin II on the determinants of glomerular ultrafiltration and proximal tubule fluid reabsorption in the rat. Circ. Res. 37: 101-110.

19. Baylis, C., W. M. Deen, B. D. Myers, and B. M. Brenner. 1976. Effects of some vasodilator drugs on transcapillary fluid exchange in renal cortex. Am. J. Physiol. 230: 11481158.

20. Steiner, R. W., B. J. Tucker, and R. C. Blantz. 1979. Glomerular hemodynamics in rats with chronic sodium depletion. Effects of saralasin.J. Clin. Invest. 64: 503-512.

21. McGiff, J. C., K. Crowshaw, and N. A. Terragno. 1970. Prostaglandin-like substances appearing in canine renal venous blood during renal ischemia. Circ. Res. 27: 765782.

22. Gotshall, R. W., J. O. Davis, E. H. Blaine, X. J. Musacchia, B. Braverman, R. Freeman, and J. A. Johnson. 1974. Increased renin release during renal arteriolar dilation in dogs. Am. J. Physiol. 227: 251-255.

23. Satoh, S., and B. G. Zimmerman. 1975. Influence of the renin-angiotensin system on the effect of prostaglandin synthesis inhibitors in the renal vasculature. Circ. Res. 36, 37(Suppl. I): 189-196.

24. Swain, J. A., G. R. Heyndricks, D. H. Boettcher, and S. F. Vatner. 1975. Prostaglandin control of renal circulation in the unanesthetized dog and baboon. Am. J. Physiol. 229: 826-830.

25. Davis, J. O., and R. H. Freeman. 1976. Mechanisms regulating renin release. Physiol. Rev. 56: 1-56.

26. Berl, T., W. L. Henrich, A. L. Erickson, and R. W. Schrier. 1979. Prostaglandins in the beta-adrenergic and baroreceptor-mediated secretion of renin. Am. J. Physiol. 236: F472-F477.

27. Blackshear, J. L., W. S. Spielman, F. G. Knox, and J. C. Romero. 1979. Dissociation of renin release and renal vasodilation by prostaglandin synthesis inhibitors. Am.J. Physiol. 237: F20-F24.

28. Seymour, A. A., and J. E. Zehr. 1979. Influence of renal prostaglandin synthesis on renin control mechanisms in the dog. Circ. Res. 45: 13-25.

29. Blantz, R. C., K. S. Konnen, and B. J. Tucker. 1976. Angiotenin II effects upon the glomerular microcirculation and ultrafiltration coefficient of the rat.J. Clin. Invest. 57: 419-434.
30. Baylis, C., and B. M. Brenner. 1978. Modulation by prostaglandin synthesis inhibitors of the action of exogenous angiotensin II on glomerular ultrafiltration in the rat. Circ. Res. 43: 889-898.

31. Ichikawa, I., and B. M. Brenner. 1979. Local intrarenal vasoconstrictor-vasodilator interactions in mild partial ureteral obstruction. Am. J. Physiol. 236: F131-F140.

32. Ichikawa, I., J. F. Miele, and B. M. Brenner. 1979. Reversal of renal cortical actions of angiotensin II by verapamil and manganese. Kidney Int. 16: 137-147.

33. Schor, N., I. Ichikawa, and B. M. Brenner. 1980. Glomerular adaptations to chronic dietary salt restriction or excess. Am. J. Physiol. In press.

34. Schor, N., I. Ichikawa, J. L. Troy, and B. M. Brenner. 1979. Effects of prostacyclin on glomerular hemodynamics. American Society of Nephrology. 12: 65A. (Abstr.)

35. Ichikawa, I., D. A. Maddox, M. G. Cogan, and B. M. Brenner. 1978. Dynamics of glomerular ultrafiltration in euvolemic Munich-Wistar rats. Renal Physiology. 1: 121-131.

36. Bell, R. D., W. L. Parry, and W. G. Grundy. 1973. Renal lymph sodium and potassium concentrations following renal vasodilation. Proc. Soc. Exp. Biol. Med. 143: 499-501.

37. Wolgast, M., E. Persson, J. Schnermann, H. Ulfendahl, and P. Wunderlich. 1973. Colloid osmotic pressure of the subcapsular interstitial fluid of rat kidneys during hydropenia and volume expansion. Pfluegers Arch. Eur. J. Physiol. 340: 123-131.

38. O’Morchoe, C. C. C., P. J. O'Morchoe, and E. J. Donati. 1975. Comparison of hilar and capsular renal lymph. Am. J. Physiol. 229: 416-421.

39. Deen, W. M., J. L. Troy, C. R. Robertson, and B. M. Brenner. 1973. Dynamics of glomerular ultrafiltration in the rat. IV. Determination of the ultrafiltration coefficient. J. Clin. Invest. 52: 1500-1508.

40. Tucker, B. J., and R. C. Blantz. 1978. Determinants of proximal tubular reabsorption as mechanisms of glomerulotubular balance. Am. J. Physiol. 235(2): F142-F150.

41. Strandhoy, J. W., C. E. Ott, E. G. Schneider, L. R. Willis, N. P. Beck, B. B. Davis, and F. G. Knox. 1974. Effects of prostaglandins $E_{1}$ and $E_{2}$ on renal sodium reabsorption and Starling forces. Am. J. Physiol. 226: 1015-1021.

42. Hall, J. E., A. C. Guyton, T. E. Jackson, T. G. Coleman, T. E. Lohmeier, and N. C. Trippodo. 1977. Control of glomerular filtration rate by renin-angiotensin system. Am. J. Physiol. 233: F366-F372.

43. Robertson, C. R., W. M. Deen, J. L. Troy, and B. M. Brenner. 1972. Dynamics of glomerular ultrafiltration in the rat. III. Hemodynamics and autoregulation. Am. J. Physiol. 223: $1191-1200$.

44. Kaloyanides, G. J., R. E. Ahrens, J. A. Shephard, and G. F. DiBona. 1976. Inhibition of prostaglandin $E_{2}$ secretion. Failure to abolish autoregulation in the isolated dog kidney. Circ. Res. 38: 67-73.

45. Arendshorst, W. J., and W. H. Beirwaltes. 1979. Renal and nephron hemodynamics in spontaneously hypertensive rats. Am. J. Physiol. 236: F246-F251.

46. Giebisch, G. 1978. The proximal nephron. In Physiology of Membrane Disorders. T. E. Andreoli, J. F. Hoffman, and D. D. Fanestil, editors. Plenum Medical Book Co., New York. 629-660. 